\title{
War on Leakers: National Security and American Democracy, from Eugene V. Debs to Edward Snowden
}

Review Number: 2074

Publish date: Thursday, 2 March, 2017

Author: Lloyd C. Gardner

ISBN: 9781620970638

Date of Publication: 2016

Price: $£ 16.58$

Pages: 336pp.

Publisher: The New Press

Publisher url: https://www.thenewpress.com/books/war-on-leakers

Place of Publication: New York, NY

Reviewer: Christopher Fuller

Despite the back cover declaring Lloyd Gardner's The War on Leakers 'the essential backstory to understand the Snowden case, NSA eavesdropping, and the future of privacy', and its subtitle promising a study 'from Eugene V. Debs to Edward Snowden,' it would be inaccurate to describe this book as a historical work. Rather, The War on Leakers occupies a space at the cusp of history, similar to Gardner's previous publication, Killing Machine: The American Presidency in the Age of Drone Warfare. By residing at the junction between current affairs, and what is yet to be classed as history in a traditional sense, Gardner demonstrates a skill for identifying pertinent topics, which are likely to animate historians for years to come. In doing so, he is able to take the opportunity to establish the initial narrative around these highly controversial and contested topics, setting a framework which future scholars will either build upon, or challenge. While this makes The War on Leakers a useful text for those looking to introduce themselves to the debates surrounding the likes of Edward Snowden and Julian Assange, the role of organizations such as WikiLeaks, and the way in which the U.S. government has sought to challenge them - this contemporary focus also serves to limit the book's overall utility.

The War on Leakers opening two chapters do an excellent job of putting contemporary leaks into context. By providing an informative overview of the expansion of the American national security state in the first half of the 20th century, and the consequent rise in secrecy and classified communications such developments wrought, Gardner effectively sets the scene for the rise of contemporary leaks and leakers. These chapters also provide a helpful explanation of the creation of the Espionage Act of 1917 - the legislative tool the Obama administration came rely upon in its forceful pursuit of those it deemed guilty of undermining America's national security through their defiance of the government's regime of secrecy. From here however, the author's desire to cut to the chase and discuss matters revolving around contemporary leakers sees the remainder of the book jump from Nixon's efforts to prosecute Daniel Ellsberg for leaking the Pentagon Papers to a focus upon the Bush Jnr., and predominantly the Obama administration. It is a jarring transition, and one which leaves many important historical developments in the intervening years uncovered.

The book's fast-forwarding to the matter that clearly animates Gardner - namely his belief that the executive 
branch and intelligence community have been abusing the powers they have accrued in the post-9/11 age has a significant impact upon the text as a historical piece of work. A combination of the classification surrounding the topics being discussed, combined with the unresolved nature of the contemporary events covered means the majority of the book's content is drawn directly from journalistic accounts. One only needs to glance at the citations to see that the bulk of the evidence used is, as the back cover explains, 'ripped from today's headlines'. This limits Gardner to repeating the arguments which have already played out in the press, meaning much of the content in the remaining chapters adds little new for anyone who has carefully followed the stories as they unfolded. It also gives the book a rather close-up focus, as opposed to the more wide-angled view one would hope a historian could bring to such a debate. It should however be noted that Gardner undertook an exhaustive job in reviewing the plethora of articles and blog posts published as the leaks discussed played out, ensuring the book provides what is probably the best summary of the press's response to leaks under the Obama administration currently available.

A further consequence of the book leaning so heavily upon the work of journalists is a significant lack of balance. At times, readers may find themselves wondering what those involved in the intelligence community, those who oversee classification procedures, or those within the executive branch who push for the prosecution of leakers may have to say. Their input however, where it is included, is predominantly drawn from the soundbites included in the press stories which are already highly critical of their methods. Furthermore, the reliance upon press reporting means the bulk of the book's analysis of leakers is limited to those whose leaks dominated their respective news cycles - Daniel Ellsberg and Edward Snowden for example. While this is effective in terms of name recognition for the book's audience, keeping the author's focus upon the most high-profile examples, it has a distorting effect. The featured leakers are revealed as noble truth tellers, seeking to expose government wrongdoing, while the executive branch's efforts to clamp down on such activity is presented as a further overextension of the national security state. Where other leakers are mentioned, they are slotted into this same dividing category of secrecy verses transparency.

One example of Gardner's simplified treatment of leakers' motives can be seen in the book's brief coverage of Stephen Kim's case. Kim is a former State Department employee who was prosecuted by the Obama administration under the Espionage Act for passing on details of a classified report on North Korea's nuclear programme. Through Gardner's sympathetic lens, Kim was a naïve official, seeking to use a time-honoured approach for mid-level experts to convey their concerns about misguided higher-level policies - talking to a reporter - who was made an example of by an overly aggressive White House. Kim's choice of Fox News' James Rosen to disclose the information to however, deserved a more critical analysis from the author. The subsequent investigation into the State Department official revealed his long-term dissatisfaction with US policy toward North Korea. 'I know I am going to be accused of being a warmonger,' Kim had noted in a rare public talk in 2006, 'but diplomacy, if not backed by the possibility of force, is very, very empty'.(1) In an email to a colleague in February 2009, four months before he passed classified details onto Rosen, Kim emailed a colleague informing him 'I am SERIOUSLY considering resigning from this entire USG business. I cannot seemingly affect change from within ... and so perhaps it is best to do it from the outside'.(2) Kim's motivation in speaking to Rosen was to undermine America's diplomatic containment of North Korea, and to pressure the US government into having to take a more militaristic policy toward the rogue state. As for Fox News, its partisan efforts to undermine the Obama administration at the time were so aggressive, reporters in Washington referred to the White House and news network as being openly 'at war'.(3) In not providing a more critical and nuanced analysis of leakers and their differing motivations, the book misses a valuable opportunity explore their role within a democratic society, something which would have made this book more enlightening and useful to both members of the public and scholars alike.

While Gardner's treatment of leakers' motives is rather general, he does do a good job of highlighting that the government has not always been so consistent in its treatment. The cases of I. Lewis Libby, David Petraeus, and James Cartwright - all granted greater leniency and spared prosecution via the Espionage Act, are compared to those of John Kiriakou, Thomas Drake, and Jeffrey Sterling. Gardner convincingly argues that the latter, whistleblowers of perceived abuses which cast the government in a negative light, received much harsher treatment in court. Cartwright's recent pardon by Obama, following the retired general's 
apparent involvement in the leaking of information about the United States' cyber campaign against Iran's nuclear programme, further supports Gardner's case. This issue is somewhat complicated however by Obama's decision to commute the sentence of Chelsea Manning, a leaker who had been sentenced to an unprecedented 35 years in prison for providing WikiLeaks with the Afghan and Iraq War logs, and over 250,000 State Department cables. This move, a surprise to many, challenges one of the accusations Gardner levels at the administration, although there are plenty who would argue the seven years of imprisonment, and extensive periods of solitary confinement Manning suffered were already punishment enough.

Perhaps the most glaring absence in The War on Leakers is the book's lack of consideration of the changing nature of technology. The staggering pace of digitization and dramatic growth of computer networks within the American government since the 1980s has transformed the way departments and officials communicate and store information. Subsequently, this has also dramatically changed the practicalities of stealing, and subsequently leaking, classified material. When drawing his comparison between Ellsberg's photocopying of parts of the 'Report of the Office of the Secretary of Defense Vietnam Task Force', and Snowden's downloading of NSA documents, Gardner makes no distinction between the former's careful selection of relevant sections of a much lengthier document, and Snowden's mass copying of what is estimated to be over one million documents. The same is true for Manning's theft, which amounted to over 650,000 unedited documents, passed directly onto WikiLeaks. Not only does the digital nature of modern communications allow for theft on such an industrial scale, but it also enables the rapid copying and distribution of such leaks - a fact born out by the existence of WikiLeaks enormous 'Public Library of U.S. Diplomacy' repository. With leaks of such a scale, it becomes much more difficult for the leakers to claim that they know the likely impact of the material they are leaking, as it is impossible for them to have a full grasp of what is contained within the mass data dumps they are making publically available. Acknowledging this change is essential in contextualizing the way in which the Obama administration has reacted, through its use, or abuse as The War on Leakers argues, of the Espionage Act. For Gardner, and those who worked with the leakers such as Glenn Greenwald and Julian Assange, the US government employs the Espionage Act as a legal tool to enable them to continue to conceal the hypocrisy of American foreign policy, and the distasteful activities undertaken by its intelligence community. Such a perspective however overlooks the more direct fact that, regardless of what policy choices may or may not be being concealed, no government could survive the regular haemorrhaging of enormous amounts of classified communications.

Despite Gardner's exclusion of the significance of technological change in changing the government's calculus in dealing with leakers, his book does successfully demonstrate how two seemingly separate issues - the rapid expansion of the intelligence community's capabilities, and the increase in the tempo and severity of leaks - are deeply intertwined. Connected to this is a further thread, perhaps the most interesting which Gardner identifies, namely the concern held by many liberal intellectuals, cited by the author in articles published in the likes of The New Yorker and The New Republic, that leaks from the likes of Snowden dangerously undermine the credibility of the modern, liberal democratic state. For some concerned liberals, Gardner argues, the actions of leakers such as Manning and Snowden, and subsequent reporting on the activities their revelations exposed by journalists such as Glenn Greenwald, is not a public service, but an attack. Such overextensions, these liberals maintain, can and should be dealt with by the internal review mechanisms of the state, such as the Intelligence Oversight Committee's investigation into the CIA's Enhanced Interrogation Program and torture, or Obama's pre-Snowden promise to review the balance between surveillance and civil liberties. Whether such investigations would ever have occurred without whistleblowing is impossible to know. But the awkward truth Gardner reveals is the desire, even among liberals, to rally around the flag when the states' integrity is challenged by leakers. The tendency to blame the messenger as opposed to the abuser suggests that there is little appetite for deep and difficult reflection, even among many scholars and intellectuals, and that there remains little appetite for reform, even when evidence of wrongdoing is forced into the public arena by leakers and their advocates in the press.

Gardner was quite right to turn his focus to the important topic of leakers and their treatment by the executive branch. How secrecy is handled, and what level of transparency is necessary is an enduring matter of importance for a liberal democracy, and one which changes in technology have forced a reassessment of. 
His decision to engage in such a contemporary matter should also be commended. As historians, it can be deeply uncomfortable to move into areas still enveloped in the fog of the present, but this matter is one of such importance and division that it cannot be left solely to journalists. Despite Pulitzer prize-winning work on the issue, time constraints and word limits have prevented a full exploration of this complex matter. Furthermore, journalists' direct involvement as potential recipients of leaked material, or as employees of institutions that deal in this currency, throws up questions as to their objectivity. In this highly contested climate, a detailed, contextualised, and even-handed study is necessary. As demonstrated by Gardner's discussion of the Espionage Act in 1917, leaking and the government's response to it has a legacy, and history can offer valuable lessons for both leakers, and those who seek to prosecute them as to the risks, costs, and benefits of doing so. However, in his rush to discuss the important events of the present, one cannot help but feel that Gardner leaves out too much of the value that a historian can add. By relying so heavily upon the press, and focusing the majority of the book on contemporary leaks and leakers, The War on Leakers adds to the noise and clamour of the current debate as another invested protagonist, as opposed to a more even-handed treatment, which would truly help place current events into context.

Taking a side and adding to the debate is, doubtless exactly what Gardner intended to do with the publication of this book, and in that pursuit, he is entirely successful. The War on Leakers is a polemical attack upon what the author sees as the over extension of the intelligence community and national security state, and the executive branch's aggressive misuse of legislation in order to maintain this state of affairs. Gardner's warnings of attacks upon the integrity of journalists seem particularly relevant in light of ongoing assault from the current administration on journalists' integrity. It suggests that the Obama administration's dogged pursuit of both leakers, and the harassment of journalists who worked with them played its own part in helping create an atmosphere in which reporters' criticism of the government can be labelled as 'fake news', while the credibility of their institutions is called into doubt by political leaders. The underlying message of Gardner's book - that those seeking to limit access to information are paranoid and hyperactive censors, while leakers like Snowden are dutiful citizens, doing their best to challenge the pernicious effects of government secrecy - deserves, and in fact requires, further exploration. The War on Leakers is an important contribution, which provides one of the best summaries of one side of the argument available for readers today. In order to drive home the book's polemical argument however, Gardner chose to focus upon recent events, leaving little space for a more wide-angled, balanced exploration of the key historical developments which led to the current situation. This book is not 'the essential backstory to understanding the Snowden case, NSA eavesdropping, and the future of privacy' its blurb suggests, and readers searching for such a book need to look elsewhere (Rahul Sagar's Secrets and Leaks, Alasdair Robert's Blacked Out, and Fred Kaplan's Dark Territory are good places to start). However, as an introduction to the debate from the side of those who see the government's actions as excessive, Gardner provides an exhaustive summary of years' worth of press reporting in a concise and accessible book.

\section{Notes}

1. 'The Current State of North Korea and the Future of the U.S.-Korea Alliance - Panel 1', YouTube, 30 September 2010 <https://www.youtube.com/watch?v=TwVlPl8BYpY [2]> [accessed 9 February 2017].Back to (1)

2. Peter Mass, 'Destroying by the Espionage Act', The Intercept, 18 February $2015<$ https://theintercept.com/2015/02/18/destroyed-by-the-espionage-act/ [3]> [accessed 9 February 2017]. Back to (2)

3. David Carr, 'The Battle Between the White House and Fox News', New York Times, 17 October 2009 <http://www.nytimes.com/2009/10/18/weekinreview/18davidcarr.html [4]> [accessed 9 February, 2017].Back to (3)

\section{Other reviews:}

PopMatters

http://www.popmatters.com/review/the-war-on-leakers-a-hell-of-a-means1/ [5]

\section{H-Diplo}

https://networks.h-net.org/node/28443/discussions/162912/h-diplo-roundtable-xviii-14-war-leakers-nationalsecurity-and 
[6]

Kirkus Reviews

https://www.kirkusreviews.com/book-reviews/lloyd-c-gardner/the-war-on-leakers/ [7]

Source URL:https://reviews.history.ac.uk/review/2074

\section{Links}

[1] https://reviews.history.ac.uk/item/171232 [2] https://www.youtube.com/watch?v=TwVlP18BYpY

[3] https://theintercept.com/2015/02/18/destroyed-by-the-espionage-act/

[4] http://www.nytimes.com/2009/10/18/weekinreview/18davidcarr.html

[5] http://www.popmatters.com/review/the-war-on-leakers-a-hell-of-a-means1/

[6] https://networks.h-net.org/node/28443/discussions/162912/h-diplo-roundtable-xviii-14-war-leakers-

national-security-and [7] https://www.kirkusreviews.com/book-reviews/lloyd-c-gardner/the-war-on-leakers/ 